\title{
Low Dose Ketamine Used for Acute Pain Management in the Emergency Department
}

\author{
Catherine Kestenian ${ }^{1,2}$, Raymund Gantioque ${ }^{1}$, Eric Snyder² \\ ${ }^{1}$ Department of Nursing, California State University of Los Angeles, Los Angeles, CA, USA \\ ${ }^{2}$ Emergency Department, Providence Cedars-Sinai Tarzana Medical Center, Tarzana, California, USA \\ Email: ckesten@calstate.edu,rgantio@calstate.edu,esnyder@ema.us
}

How to cite this paper: Kestenian, C., Gantioque, R. and Snyder, E. (2020) Low Dose Ketamine Used for Acute Pain Management in the Emergency Department. Open Journal of Emergency Medicine, 8, 21-30. https://doi.org/10.4236/ojem.2020.81003

Received: February 5, 2020

Accepted: March 1, 2020

Published: March 4, 2020

Copyright $\odot 2020$ by author(s) and Scientific Research Publishing Inc. This work is licensed under the Creative Commons Attribution International License (CC BY 4.0).

http://creativecommons.org/licenses/by/4.0/ (c) (i) Open Access

\begin{abstract}
The use of opioid analgesics has created an opioid addiction epidemic in the United States and around the world. One of the main responsibilities of the emergency department is to address acute pain. In this paper we examine the use of low dose ketamine as a safe substitute for opioid analgesics. Types of pain are identified using prior established taxonomy, followed by discussing types of management and treatments. The opioid epidemic and its societal implications are considered. We also examine the side effects of ketamine and the use of ketamine as an adjunct to analgesics used for pain control. Recommendations and considerations for the use of ketamine are suggested, and a low dose ketamine administration sample hospital policy is reviewed.
\end{abstract}

\section{Keywords}

Low Dose Ketamine, Sub-Dissociative Ketamine, Pain Control, Emergency Department, Opioids

\section{Introduction}

For many years, opioid analgesics have been the first line of choice for treatment of acute pain in emergency departments around the world [1]. Unfortunately, it has caused a rise in opioid addiction and increased mortality rate, which has been linked to opioid prescriptions [2]. Because of this, the United States and many countries have been attempting to address what has become an opioid epidemic [3] [4]. The treatment of acute pain has been an important circumstance around the opioid epidemic, and emergency departments have been the most significantly frequent contact point between the healthcare providers and the public [4]. 
Ketamine was first introduced in 1965 and has fluctuated in popularity since its introduction [5]. Since its release for commercial use, ketamine in low dosage has been used for controlling pain during prehospitalization, hospitalization and postoperative stages of care. It has not been consistently utilized for addressing pain, and due to the chronic use of opioid analgesics, we now have an opioid addiction epidemic. As an unintended consequence, the amount of lives lost constitutes a public health crisis. A review of literature identifies the evidence of the efficacy and safety of using low dose ketamine as an alternative to opioid analgesics [6] [7] [8] [9].

\section{Background of Acute Pain}

Pain is defined as a physiologic response to painful stimuli on a body's surface and is transmitted through the spinal cord to the brain where it is perceived [10]. Pain is a multifaceted sensation felt through the use of the nervous system in-order to be made aware of an abnormality in homeostasis. The change in condition may be physical, psychological, may be new (acute) or prolonged (chronic). The continued development of the clinical definitions of acute and chronic pain and their classifications and sub-classifications are important to society for use as a tool for future prevention and treatment of pain [10].

\subsection{Types of Acute Pain/Pathophysiology}

Reference [10] applied the prior established multidimensional framework for taxonomy of chronic pain by Dworkin, et al. (2016) to the subject of acute pain. Reference [10] used the framework of the 5 dimensions to put into perspective the characteristics of acute pain. The 5 dimensions include: 1) core diagnostic criteria; 2) common features; 3 ) common medical and psychiatric comorbidities; 4) neurobiological, psychological, and functional consequences; 5) putative neurobiological, psychosocial mechanisms, risk factors, and protective factors [11]. The taxonomy development by Dworkin, et al. (2016) was purposed to examine and address the classification of pain with an evidence-based approach. As a result, the multidimensional framework was conceptualized as a tool used to organize characteristics of pain hierarchically [10].

Pain can be felt and identified in all body systems that have neurological pathways. The pathophysiological mechanisms that are identified as enabling pain include inflammatory, nociceptive (sensation), neuropathic and ischemic [10] [11].

\subsection{Treatment/Management}

The measurement and treatment of acute pain starts with the initial assessment process. In the emergency department, the mechanism or cause of the pain should first be established. Then the assessment of the patient's pain is completed by using rating scales which include but not limited to visual, numeric and observed scales [10] [12]. Next, the method of treatment, which includes 
both nonpharmacological and pharmacological is personalized to reach optimal treatment of acute pain.

\subsection{Opioid Crisis/Addiction}

The opioid crisis in the United States has become significantly worse over the years. The mortality rate has risen by $9.6 \%$ from 2016 to 2017 for a total of 79,237 and approximately $67.8 \%(47,600)$ of the total overdoses were due to prescription drugs [13].

The treatment of pain has been focused on pharmacological interventions based on subjective data for the past 2 decades [14]. Furthermore, the pharmaceutical industry has been indicted in the falsification of studies completed for opioid medications in order to persuade and influence prescribers to write for opioids at higher doses and frequencies. Congressional hearings started in 2018 have addressed big pharmaceutical companies such as Perdue Pharma and pursued criminal charges against them [14]. After years of litigation, the Stackler family, owners of Purdue Pharmaceuticals were mandated to pay 3 billion dollars total in damages. In the same settlement the Stackler family agreed to dissolve the company, forming a new one in order to continue to operate, while completely relinquishing control of the company [15]. The Stacklers and Purdue Pharma are also under investigation by the Department of Justice for criminal charges. The criminal charges have been filed under the "continuing criminal enterprise" statutes. Indicating the Stacklers were aware of specific physicians prescribing opioids illegally and failing to report them [16]. These are statutes that are usually used when prosecuting drug dealers. The original 3-billion-dollar settlement was only the first settlement of the 50 states. Many state attorneys' have spoken out about their intentions to continue litigation [16]. The outcomes from the litigation prove that the opioid epidemic was manufactured and real, and the people and companies that helped fuel it will be held responsible. It is now a problem in the hands of the healthcare field and by using SDK instead of opioid analgesics we can help stop the epidemic instead of fueling it.

\section{Indications for Administration of Low Dose Ketamine}

Indications for pain management are wide ranging and stem from the root cause of the pain. Ketamine at a low dose, has been used as a pharmacological intervention for pain relief in the emergency department during procedural sedation for many years [17]. Low dose ketamine in the emergency department may be especially useful as an intervention for patients with refractory pain due to high tolerance levels to opioid analgesics that may also have multifactorial components such as neuropathic pain, depression and inflammatory processes [7]. Sub-dissociative dose of ketamine (SDK) also known as low dose ketamine has been shown to have successful pain control in chronic non-traumatic chest pain, musculoskeletal pain, vaso-occlusive pain and renal colic pain in the emergency department [18]. 


\section{Pharmacological Acute Pain Management in the Emergency Department}

1) Opioid analgesics used for Acute pain

a) Morphine

Morphine is the most commonly used narcotic medication for acute pain control in the emergency department and as such it is also the most widely available [19] [21]. The most commonly used and lowest dosage of morphine is $0.1 \mathrm{mg}$ per kilogram administered intramuscularly or intravenously (IM, IV) per dose [19]. Morphine has been shown to have adverse side effects such as respiratory depression and over-sedation [19].

b) Hydromorphone

Hydromorphone has been shown to have greater potency when compared to morphine, which provides greater relief for acute pain in the emergency department [22]. A retrospective chart review by Priano, Faley, Procopio, Hewitt, \& Feldman (2017) of patients' in the emergency department that received morphine vshydromorphone intravenously, indicated that the potency ratio of morphine to hydromorphone was 7:1. The patients that received morphine had a lower total opioid medication administered than patients that received Hydromorphone. For example, if a patient received four milligrams of Morphine versus one milligram of Hydromorphone that would equal 4:7 of opioid analgesic [23]. Furthermore, the weight-based dosing for the emergency department for acute pain is morphine $(0.1 \mathrm{mg} / \mathrm{kg})$ and hydromorphone $(0.015 \mathrm{mg} / \mathrm{kg})$ [23]

2) Non-opioids

a) Ketamine

Ketamine is considered a non-opioid analgesic medication and has a molecular composition of N-methyl-D-aspartate (NMDA) and functions as a glutamate receptor antagonist [24]. Unlike opioid analgesic medications that function by activating $\mathrm{Mu}$ receptors and are known agonists, low dose ketamine has a very low rate of adverse effects on the respiratory drive caused by over-sedation [9] [21] [24]. The characteristics of the molecular compound of ketamine and the low rate of adverse effects in non-dissociative dosing make ketamine the deal option for treatment of many types of pain. Cancer patients with chronic and breakthrough pain have responded well to low-dose ketamine treatment, without adverse side effects of hypoxia and respiratory depression [25]. Ketamine has multiple methods of effect that include hypnotic, analgesic, and amnesic making it the only drug to have all three properties in one [26].

Ketamine also has many treatment routes including intranasal treatment, SQ, IM, PO, IV treatment. Intranasal ketamine is especially useful as an adjunct treatment for refractory pain in cancer patients that are unable to swallow medication properly and may need an alternative route for treatment [27]. In one study overviewing Ketamine's potential benefits and risks it was considered the preferred medication used to treat pain in patients with hemodynamic instability [26]. 


\section{Comparison in the Reduction of Acute Pain}

The risks of using opioid analgesics such as hydromorphone and morphine for patients to treat short-term acute pain may be too great on our society for providers to ignore [2]. The utilization of non-opioid analgesic may provide practitioners the tool they need to treat acute pain while helping fight the opioid epidemic [2]. Despite the admission by most studies that further evaluation of ketamine in all its forms is necessary, low dose, sub-dissociative ketamine use has been identified as a valid alternative for treating acute pain either as an adjunct or in place of opioid analgesics [1] [25]. In a single-center, double-blinded, randomized study the effectiveness of ketamine versus hydromorphone was investigated by allowing patients to use breakthrough opioid analgesics while on either a ketamine or hydromorphone patient controlled analgesic (PCA). The patients using ketamine used less breakthrough opioid analgesics and required less oxygenation, yet the study concluded further studies were necessary for to investigate the tolerability of ketamine vs traditional opioid based PCA [1]. The use of ketamine as an alternative for the acute exacerbation of chronic pain related to malignant disease was reviewed and ketamine although ketamine was effective, the authors concluded that more randomized controlled studies were needed [25].

A comprehensive systematic review and meta-analysis of randomized controlled trials compared intravenous opioid analgesics to low-dose ketamine for relief of acute pain in the emergency department and concluded that ketamine is not inferior to morphine and was a viable alternative to opioids in the emergency department [28]. A prospective, randomized, double-blind trial held in an emergency department for patients from the age of 18 - 55 that suffered acute, moderate to severe, abdominal, flank and musculoskeletal pain found that sub-dissociative doses of ketamine were successful in treating pain in comparison to intravenous morphine with a confidence index of $95 \%$ and $\mathrm{P}<0.05$ denoting statistical significance [21].

A double-blind randomized placebo trial found that ketamine, as an adjunct, was effective in acute pain control and lowered the overall opioid dose utilized by the patients in the ketamine group [29]. Although further studies are needed to further evaluate the efficacy of ketamine versus other opioid analgesics with higher confidence, it is important to recognize the lower demand and lower dose administration of opioid analgesics while using ketamine for acute pain control [29].

\section{Considerations for Practitioners and Nurses}

If low dose ketamine is used in the emergency department as a pharmacological treatment for pain, it is important to take into consideration the risks and benefits, least effective and most effective uses. Low dose ketamine is an effective pharmacological treatment of pain by itself and as an adjunct to opioids [7] [30] because it is a non-competitive NMDA antagonist and it does not interfere with receptors used by opioids [7] [19] [30]. As an adjunct therapy, it is especially important to consider the dosing of opioids in order to prevent opioid-ketamine 
adverse reactions. The need for opioids such as morphine may be reduced by $26 \%-60 \%$ when ketamine is used as an adjunct [30]. Non-severe adverse effects that need to be monitored and treated due to low dose ketamine include nausea, dizziness, drowsiness, vomiting, decreased oxygen saturation [19] [28]. Opioids such as morphine also have similar non-severe adverse effects [19] [28], but their use also worsens the opioid epidemic [2] [14].

There have been concerns about ketamine causing increased intercranial pressure (ICP) since the initial reports of patient's suffering increased ICP came out during the 1970's. Ketamine was stigmatized and medical literature from then on contraindicated the use of ketamine for patients with neurological disorders [31]. Upon re-examination of the 1970's studies reporting the increased ICP it was found that the patients requiring intervention all had preexisting hydrocephalus with no intact cerebral spinal fluid flow [31]. The increase in ICP is caused by increased blood flow due to cerebral vasodilation, preserving or improving cerebral perfusion [20] [31]. Therefore increased ICP is only contraindicated in use for patients with preexisting hydrocephalus.

The risk of transient hypoxia or major hypoxic adverse reactions is very low. In one study SDK was used to treat acute pain in an emergency department for 2 years on a total of five hundred thirty patients, of which only 7 patients (1.5\%) had a hypoxic adverse reaction [32]. Although SDK or low dose ketamine is a promising alternative to the monotherapy focused use of opioids more widely practiced today, the administration of SDK may prove to be cumbersome depending on several factors. The administration of ketamine by registered nurses may have guidelines published by the state board. These guidelines are considered nursing protocols and must be adhered to by registered nurses in each state. For example, the Texas Board of Nursing (BON) published a statement requiring the orders for SDK to be written by anesthesiologists or pain specialists, which is then to be given by the registered nurse in the emergency department setting [20]. This type of guideline severely limits registered nurses in Texas from administering SDK. Hospital policy and procedures are another level of guidance to be considered, as they almost always further dictate nursing procedure. Most protocols and guidelines whether on the state or organizational level, all concur that monitoring parameters include hemodynamic, mental status, pulse oximetry, and telemetry [20]. The experience, expertise, and knowledge of the nurse administering the SDK should also be taken into careful consideration in the emergency setting. Although in many hospital policy and procedures the administration of SDK is still considered conscious sedation, hospital policies do not all require one on one monitoring for administering SDK [33]. Although the dose of the ketamine should be the deciding factor of the level and length of monitoring, many physicians and practitioners are still reluctant to use SDK due to the fear of lacking resources.

\section{Recommendations}

An Emergency Department in a medium sized community hospital adapted and 
initiated a policy and procedure protocol regarding the administration of low dose ketamine. While keeping in mind their mission and core values, they created a policy that ensured safe and effective pain management using low dose ketamine $(0.3 \mathrm{mg} / \mathrm{kg}$ pushed over 5 minutes $)$ as an alternative or adjunct to the use of opioid analgesics. Prior to giving the medication, the patient must be on continuous telemetry, pulse oximetry, hemodynamic monitoring. After administering the ketamine, the patient must be monitored for 60 minutes post last dose. Although the patient needs careful and close monitoring, the policy does not require the patient to be monitored 1:1 [33] (see Table 1).

Table 1. Low Dose Ketamine Use in the Emergency Department.

\begin{tabular}{|c|c|}
\hline $\begin{array}{l}\text { Low Dose Ketamine Use in } \\
\text { the Emergency Department }\end{array}$ & Procedure/General Instructions \\
\hline \multirow{5}{*}{ Indications } & 1) Acute Traumatic pain (e.g., fractures, lacerations, dislocations, burns) \\
\hline & 2) Acute non-traumatic pain (e.g., abdominal, flank, back, headache) \\
\hline & 3) Chronic pain conditions \\
\hline & 4) Analgesic resistant pain \\
\hline & 5) Sickle cell pain crisis [34] \\
\hline \multirow{10}{*}{ Contraindications } & 1) Schizophrenia/psychosis \\
\hline & 2) Age $<3$ months or $>75$ years \\
\hline & 3) Pregnant/breastfeeding \\
\hline & 4) Hypersensitivity to ketamine \\
\hline & 5) Active chest pain, ischemia, acute heart failure (HF) \\
\hline & 6) Advanced liver disease \\
\hline & 7) Unstable Vitals: \\
\hline & a) Systolic Blood pressure $<90$ or $>180$ \\
\hline & b) Heart rate $<50$ or $>150$ \\
\hline & c) Respiratory rate $<10$ or $>30[21]$ \\
\hline Medication Adminstration & 1) The medication must be administered by a registered nurse [21] \\
\hline Dosing & $\begin{array}{l}\text { 1) } 0.3 \mathrm{mg} / \mathrm{kg} \text { of ketamine slow intravenous push over } 5 \text { minutes } \\
\text { a) May repeat dose as needed every } 30 \text { minutes [21] }\end{array}$ \\
\hline \multirow{3}{*}{ Monitoring } & 1) Document pain level and vital signs prior to administration \\
\hline & 2) All patients to be monitored using continuous pulse oximetry and telemetry \\
\hline & Reassess pain level and vital signs 30 minutes after administration [33] \\
\hline \multirow{4}{*}{ Management of Adverse Reactions } & 1) Nausea/vomiting: anti-emetic per physician order \\
\hline & 2) Respiratory: repositioning, supplemental oxygen, suction, bag-valve mask \\
\hline & Agitation, hallucinations: maintain calm quite environment, dim \\
\hline & lighting, benzodiazepine [33] \\
\hline \multirow{4}{*}{ Discharge } & $\begin{array}{l}\text { 1) The patient should be observed at least } 60 \text { minutes beyond final drug administration and } \\
\text { until patient attains pretreatment levels of verbalization and awareness, and purposeful } \\
\text { neuromuscular activity seems reasonable }\end{array}$ \\
\hline & $\begin{array}{l}\text { 2) Patient should be advised that they may experience ataxia for hours and that family } \\
\text { observation is warranted }\end{array}$ \\
\hline & 3) Patient should be advised to avoid driving a motor vehicle upon discharge for at least 8 hours \\
\hline & $\begin{array}{l}\text { a) An effort will be made to provide safe transportations, and/or the patient will be held in } \\
\text { the ED until safe discharge can be made [33] }\end{array}$ \\
\hline
\end{tabular}




\section{Conclusion}

Pain is the most common complaint stated by patients in the emergency department, and the unsuccessful treatment of pain can exacerbate any accompanying diagnosis, therefore, it is of the utmost importance for providers to treat pain using a safe and proven alternative to opioid analgesics. Improper management of acute and chronic pain with opioid analgesics can be costly to the healthcare system and the society. The use of low dose ketamine for pain management in the emergency department is rapidly growing because it has proven to be effective in pain management compared to opioid analgesics such as morphine sulfate and hydromorphone. As providers attempt to effectively treat pain, they must take into consideration the adverse effects of using opioid analgesics and look to viable alternatives such as low dose ketamine. Although more studies are necessary to further investigate the effectiveness of ketamine in all doses, forms and in different clinical settings, studies have provided confidence in the use of low dose ketamine in the emergency department. Ketamine use in the emergency department has resulted in effective pain management as an adjunct resulting in less use of opioids. This review of literature helps put into perspective the danger of the opioid epidemic, the role of providers and the emergency department in treating pain, and the need for providers to use proven alternatives such as low dose ketamine for pain control.

\section{Conflicts of Interest}

The authors declare no conflicts of interest regarding the publication of this paper.

\section{References}

[1] Takieddine, S.C., Droege, C.A., Ernst, N., Droege, M.E., Webb, M., Branson, R.D., et al. (2018) Ketamine versus Hydromorphone Patient-Controlled Analgesia for Acute Pain in Trauma Patients. Journal of Surgical Research, 225, 6-14. https://doi.org/10.1016/j.jss.2017.12.019

[2] Strayer, R.J., Motov, S.M. and Nelson, L.S. (2017) Something for Pain: Responsible Opioid Use in Emergency Medicine. The American Journal of Emergency Medicine, 35, 337-341. https://doi.org/10.1016/j.ajem.2016.10.043

[3] Pourmand, A., Jasani, G., Shay, C. and Mazer-Amirshahi, M. (2018) The Evolving Landscape of Acute Pain Management in the Era of the Opioid Crisis. Current Pain and Headache Reports, 22, Article No. 73. https://doi.org/10.1007/s11916-018-0728-y

[4] Sobel, R.M. and Steck, A.R. (2017) Low Dose Ketamine in the Age of Opioids. The American Journal of Emergency Medicine, 35, 917-918. https://doi.org/10.1016/j.ajem.2017.03.062

[5] Porter, S.B. (2019) Perioperative Ketamine for Acute Analgesia and Beyond. Romanian Journal of Anaesthesia and Intensive Care, 26, 67-73.

[6] Andolfatto, G., Innes, K., Dick, W., Jenneson, S., Willman, E., Stenstrom, R., et al. (2019) Prehospital Analgesia with Intranasal Ketamine (PAIN-K): A Randomized Double-Blind Trial in Adults. Annals of Emergency Medicine, 74, 241-250. 
https://doi.org/10.1016/j.annemergmed.2019.01.048

[7] Bell, R.F. and Kalso, E.A. (2018) Ketamine for Pain Management. PAIN Reports, 3, e674. https://doi.org/10.1097/PR9.0000000000000674

[8] Carver, T.W., Kugler, N.W., Juul, J., Peppard, W.J., Drescher, K.M., Somberg, L.B., et al. (2019) Ketamine Infusion for Pain Control in Adult Patients with Multiple Rib Fractures. Journal of Trauma and Acute Care Surgery, 86, 181-188. https://doi.org/10.1097/TA.0000000000002103

[9] Kirschner, J.M. and Hunter, B.R. (2019) Is Low-Dose Ketamine an Effective Alternative to Opioids for Acute Pain? Annals of Emergency Medicine, 73, 47-49. https://doi.org/10.1016/j.annemergmed.2018.11.001

[10] Kent, M.L., Tighe, P.J., Belfer, I., Brennan, T.J., Bruehl, S., Brummett, C.M., et al. (2017) The ACTTION-APS-AAPM Pain Taxonomy (AAAPT) Multidimensional Approach to Classifying Acute Pain Conditions. Pain Medicine, 18, 947-958. https://doi.org/10.1093/pm/pnx019

[11] Dworkin, R.H., Bruehl, S., Fillingim, R.B., Loeser, J.D., Terman, G.W. and Turk, D.C. (2016) Multidimensionsal Diagnostic Criteria for Chronic Pain: Introduction to the ACTTION-American Pain Society Pain Taxonomy (AAPT). The Journal of Pain, 17, T1-T9. https://doi.org/10.1016/j.jpain.2016.02.010

[12] Davis, W.D., Davis, K.A. and Hooper, K. (2019) The Use of Ketamine for the Management of Acute Pain in the Emergency Department. Advanced Emergency Nursing Journal, 41, 111-121. https://doi.org/10.1097/TME.0000000000000238

[13] Center for Disease Control and Prevention. Drug Overdose Deaths (27 June 2019). https://www.cdc.gov/drugoverdose/data/statedeaths.html

[14] Bernard, S.A., Chelminski, P.R., Ives, T.J. and Ranapurwala, S.I. (2018) Management of Pain in the United States-A Brief History and Implications for the Opioid Epidemic. Health Services Insights, 11. https://doi.org/10.1177/1178632918819440

[15] Hoffman, J. (2019) Purdue Pharma Tentatively Settles Thousands of Opioid Cases. New York Times, 19 September 2019.

https://www.nytimes.com/2019/09/11/health/purdue-pharma-opioids-settlement.ht $\underline{\mathrm{ml}}$

[16] Randazzo, S. (2019) Purdue Pharma in Talks With Justice Department to Resolve Criminal, Civil Probes. The Wall Street Journal, 6 September 2019, Purdue Pharma in Talks with Justice Department to Resolve Criminal, Civil Probes.

[17] Morrison, T., Carender, C., Kilbane, B. and Liu, R.W. (2017) Procedural Sedation with Ketamine versus Propofol for Closed Reduction of Pediatric Both Bone Forearm Fractures. Orthopedics, 40, 288-294. https://doi.org/10.3928/01477447-20170824-01

[18] Motov, S., Drapkin, J., Likourezos, A., Beals, T., Monfort, R., Fromm, C. and Marshall, J. (2018) Continuous Intravenous Sub-Dissociative Dose Ketamine Infusion for Managing Pain in the Emergency Department. Western Journal of Emergency Medicine, 19, 559-566. https://doi.org/10.5811/westjem.2017.12.36174

[19] Mahshidfar, B., Mofidi, M., Fattahi, M., Farsi, D., Moghadam, P.H., Abbasi, S. and Rezai, M. (2017) Acute Pain Management in Emergency Department, Low Dose Ketamine versus Morphine, a Randomized Clinical Trial. Anesthesiology and Pain Medicine, in press. https://doi.org/10.5812/aapm.60561

[20] Pourmand, A., Mazer-Amirshahi, M., Royall, C., Alhawas, R. and Shesser, R. (2017) Low Dose Ketamine Use in the Emergency Department, a New Direction in Pain Management. The American Journal of Emergency Medicine, 35, 918-921. https://doi.org/10.1016/j.ajem.2017.03.005 
[21] Motov, S., Rockoff, B., Cohen, V., Pushkar, I., Likourezos, A., Mckay, C., et al. (2015) Intravenous Subdissociative-Dose Ketamine Versus Morphine for Analgesia in the Emergency Department: A Randomized Controlled Trial. Annals of Emergency Medicine, 66, 222-229.e1. https://doi.org/10.1016/j.annemergmed.2015.03.004

[22] Cisewski, D.H. and Motov, S.M. (2019) Essential Pharmacologic Options for Acute Pain Management in the Emergency Setting. Turkish Journal of Emergency Medicine, 19, 1-11. https://doi.org/10.1016/j.tjem.2018.11.003

[23] Priano, J., Faley, B., Procopio, G., Hewitt, K. and Feldman, J. (2017) Adjunct Analgesic Use for Acute Pain in the Emergency Department. Hospital Pharmacy, 52, 138-143. https://doi.org/10.1310/hpj5202-138

[24] Jonkman, K., Dahan, A., Donk, T.V.D., Aarts, L., Niesters, M. and Velzen, M.V. (2017) Ketamine for pain. F1000Research, 6, 1711. https://doi.org/10.12688/f1000research.11372.1

[25] Brockett-Walker, C. (2019) The Use of Ketamine as an Adjunct to Treating Opioid Refractory Cancer-Related Pain in the Emergency Department. Advanced Emergency Nursing Journal, 41, 101-106. https://doi.org/10.1097/TME.0000000000000244

[26] Gao, M., Rejaei, D. and Liu, H. (2016) Ketamine Use in Current Clinical Practice. Acta Pharmacologica Sinica, 37, 865-872. https://doi.org/10.1038/aps.2016.5

[27] Singh, V., Gillespie, T.W. and Harvey, R.D. (2018) Intranasal Ketamine and Its Potential Role in Cancer-Related Pain. Pharmacotherapy. The Journal of Human Pharmacology and Drug Therapy, 38, 390-401. https://doi.org/10.1002/phar.2090

[28] Karlow, N., Schlaepfer, C.H., Stoll, C.R.T., Doering, M., Carpenter, C.R., Colditz, G.A., et al. (2018) A Systematic Review and Meta-Analysis of Ketamine as an Alternative to Opioids for Acute Pain in the Emergency Department. Academic Emergency Medicine, 25, 1086-1097. https://doi.org/10.1111/acem.13502

[29] Bowers, K.J., Mcallister, K.B., Ray, M. and Heitz, C. (2017) Ketamine as an Adjunct to Opioids for Acute Pain in the Emergency Department: A Randomized Controlled Trial. Academic Emergency Medicine, 24, 676-685. https://doi.org/10.1111/acem.13172

[30] Lee, E.N. and Lee, J.H. (2016) The Effects of Low-Dose Ketamine on Acute Pain in an Emergency Setting: A Systematic Review and Meta-Analysis. PLoS ONE, 11, e0165461. https://doi.org/10.1371/journal.pone.0165461

[31] Green, S.M., Andolfatto, G. and Krauss, B.S. (2015) Ketamine and Intracranial Pressure: No Contraindication Except Hydrocephalus. Annals of Emergency Medicine, 65, 52-54. https://doi.org/10.1016/j.annemergmed.2014.08.025

[32] Ahern, T.L., Herring, A.A., Anderson, E.S., Madia, V.A., Fahimi, J. and Frazee, B.W. (2015) The First 500: Initial Experience with Widespread Use of Low-Dose Ketamine for Acute Pain Management in the ED. The American Journal of Emergency Medicine, 33, 197-201. https://doi.org/10.1016/j.ajem.2014.11.010

[33] Providence St. Joseph Health (2018) Low Dose Ketamine Use in the Emergency Department. https://phs-captmc.policystat.com/policy/5762919/

[34] Galinski, M., Dolveck, F., Combes, X., Limoges, V., Smaïl, N., Pommier, V., et al. (2007) Management of Severe Acute Pain in Emergency Settings: Ketamine Reduces Morphine Consumption. The American Journal of Emergency Medicine, 25, 385-390. https://doi.org/10.1016/j.ajem.2006.11.016 